\title{
RESEARCH AND RESTORATION OF INLAND WATERS OF DAGESTAN AND THE TEREK RIVER IN ORDER TO INCREASE FISH PRODUCTION
}

\author{
ИССЛЕДОВАНИЕ И ВОССТАНОВЛЕНИЕ ВНУТРЕННИХ ВОДОЕМОВ ДАГЕСТАНА \\ И РЕКИ ТЕРЕК В ЦЕЛЯХ УВЕЛИЧЕНИЯ РЫБОПРОДУКТИВНОСТИ
}

\author{
S.I. Khizrieva, student \\ С.И. Хизриева, студентка \\ E-mail: saimat140992@mail.ru
}

\begin{abstract}
N.M. Abdullaeva, Candidate of Biological Sciences
Н. М. Абдуллаева, кандидат биологических наук E-mail: caca1@yandex.ru
\end{abstract}

\author{
Dagestan State University, Makhachkala, Russia \\ Дагестанский государственный университет, Махачкала, Россия
}

\begin{abstract}
The rational use of fish stocks and increase their productivity is one of the most important and urgent problems of fisheries. One of the important areas in the fishing and for the reproduction of fish on the west coast of the Caspian Sea is the basin of the Terek River. For long period (over 40 years) without the required amount of water and in the absence of improvement measures in reservoirs downstream of the Terek River deteriorated environmental conditions. Efficiency and productivity of the natural reproduction of fish fell. To raise the value of water bodies requires the implementation of integrated fisheries management activities, and thereby restore the original state and to improve water bodies.
\end{abstract}

\section{АННОТАЦИЯ}

Рациональное использование запасов рыб и повышения их продуктивности представляет одну из важнейших и актуальных рыбохозяйственных проблем. Одним из ценных районов в промысловом и в воспроизводственном отношении рыб на западном побережье Каспийского моря является бассейн реки Терек. За длительное время эксплуатации (более 40 лет) без необходимого объема воды и в условиях отсутствия мелиоративных мероприятий в водоемах низовьев реки Терек ухудшились экологические условия. Эфффективность естественного воспроизводства и рыбопродуктивность рыб упала. Для поднятия значения водоемов требуется осуществление комплексных рыбохозяйственных мероприятий, и тем самым, вернуть и улучшить исходное состояние водоемов.

\section{KEY WORDS}

Fish fauna; Hydrology; Fish production; Regulation; Water logging; Fishing; Juveniles.

КЛЮЧЕВЫЕ СЛОВА

Ихтиофауна; Гидрология; Рыбопродуктивность; Зарегулирование; Заболачивание; Промысел; Молодь.

Изучение рыбохозяйственного состояния внутренних водоемов Дагестана (Аракумские - 16 тыс. га, Нижнетерские - 13 тыс.га., Каракольские - 13 тыс.га., Южный Аграхан - 12,4 тыс.га.) и перспективы их использования в настоящее время занимает одно из важных мест в ихтиоценозе Дагестанской республики.

Цель исследования - оценка снижения уровня естественного воспроизводства, запасов и уловов проходных, полупроходных и озерно-речных рыб, а также научное обоснование пути увеличения эффективности естественного воспроизводства, запасов и уловов рыб в водоемах.

Рациональное использование запасов рыб внутренних водоемов и повышения их 
продуктивности представляет одну из важнейших и актуальных рыбохозяйственных проблем [8]. Одним из ценных районов в промысловом и в воспроизводственном отношении проходных, полупроходных и озерно-речных рыб на западном побережье Каспийского моря является бассейн реки Терек [1].

Гидрологический режим Терека своеобразен. Он обуславливает интенсивные изменения морфологии водоемов дельтового пространства, а время от времени вызывает коренное переустройство всей гидрографической структуры низовьев реки. Разливы мелеют, они позже зарастают водной растительностью, заболачиваются и отмирают, тем самым, вызывая затопления новых земель. Терек ежегодно от 16 до 20 млн.т. твердых взвесей откладывает в дельте, ложа реки поднимается и в результате образуется подпор воды, что приводит к прорыву вала на каком-то участке русла реки. Так, река Терек в прошлом веке дважды менял направление своего русла. К настоящему времени пропускная способность устье реки в районе Прорези уменьшилась до250 м³, а при половодье расходы воды Терека ниже Каргалинской плотины составляют 800-900 $\mathrm{m}^{3} / \mathrm{c}$, которые способствуют прорыва вала и затоплению населенных пунктов и сельхозугодий.

По литературным данным до середины восьмидесятых годов водоемы функционировали рентабельно. Промысловый лов здесь осуществляли 136 рыбака с использованием 12 тыс.шт. озерных вентерей, 1,4 тыс. шт. ставных сетей, а уловы колебались от 548 до 709 т. При этом доля среди озерно-речных рыб доминировали сом и щука (до 36,6\%) [1].

Промысловые уловы полупроходных и хищных видов рыб в рассматриваемых водоемах базировались в основном на старших возрастных группах. Например, в промысловых уловах рыбы в возрасте от 4 до 6 лет составляли 70\%. Для большинства видов рыб был характерен широкий, до 12-13 групп, возрастной ряд, с устойчивыми по годам показателями длины и массы тела. Численность молоди полупроходных видов рыб колебалась от 365 до 61 млн. экз.

За длительное время эксплуатации (более 40 лет) без необходимого объема воды и в условиях отсутствия мелиоративных мероприятий в водоемах низовьев р. Терек ухудшились экологические условия. Отсутствие водообмена в отдельных участках водоемов привело к бурному зарастанию мягкой и жесткой водной растительности, образованию застойных и сероводородных зон, появлению на некоторых участках водоемов зон гипоксии. Все эти негативные явления способствовали снижению численности нерестовых и зимовальных миграций проходных и полупроходных рыб и к сокращению нерестовых угодий полупроходных и озерно-речных рыб. Эфффективность естественного воспроизводства полупроходных рыб упала от 356-490 млн. эк3. до 35-67 млн. экз., а озерно-речных рыб - от 37-61 млн. экз. до 17-54 млн. экз., промысловые уловы всех видов рыб снизились с 598-709 до 68 т. Наряду со снижением общих уловов резко изменился их качественный состав в сторону сокращения ценных видов рыб. Уловы полупроходных видов рыб (сазан, лещ и др.) не превышают 22,3\% от общего вылова, воблы - 0,2\%, судака - 0,01\%. Возрастные ряды промысловых рыб стали короткими, основу улова составляют младшие возрастные категории (3-, 4-летки). Также уменьшились средние линейно-весовые показатели (рис. 1.). Рыбопродуктивность водоемов снизилась с 34,9 до 1,9 кг/га $[1,10]$.

\section{МАТЕРИАЛ И МЕТОДЫ ИССЛЕДОВАНИЯ}

Были использованы методики Монастырского [8], Чугуновой [11], Правдина [9], Коблицкой [4], Кушнаренко [6], Малкина [7].

Объектом для исследований были промысловые уловы рыб, молодь полупроходных и некоторых проходных рыб, собранные в водоемах в период с марта по октябрь 2004-2011 гг. Взрослые рыбы подвергались биологическому анализу с измерением длины и определением: веса, пола, стадии зрелости гонад, плодовитости, взятием чешуи и лучей соответствующих плавников для определения возраста. Брались пробы гонад для определения абсолютной плодовитости и гистологических срезов - для 
выяснения времени созревания половых продуктов. В рассматриваемых водоемах собрано 411 проб молоди полупроходных, проходных и озерно - речных рыб. Пробы молоди собирались в рыбоходах и непосредственно в водоемах для определения эффрективности размножения рыб. Видовой состав рыб определялся по Коблицкой [4].

Линейные размеры определялись в чашках Петри на миллиметровой бумаге, весна торзионных весах. Коэфффициент промвозврата для каждого вида молоди рыб определялся по Кожину[5]. Места нереста определяли по наличию отловленной икры, а сроки нереста по присутствию в уловах текущих производителей рыб.

Оценка численности промысловых рыб в рассматриваемых водоемах определялась биостатическим методом Монастырского [8], дополненного Чугуновым [11], Дементьевой [3].

\section{РЕЗУЛЬТАТЫ ИССЛЕДОВАНИЯ}

Проведенный анализ показывал, что в ихтиоценозе рассматриваемых водоемов произошли значительные структурные изменения, проявившиеся в замещении ценных промысловых видов рыб короткоцикличными, малоценными и непромысловыми видами. В целом можно констатировать уменьшение биомассы ценных промысловых видов рыб (судак, сазан, вобла, кутум, рыбец, лещ, жерех, сом) и замещение их малоценными видами (линь, окунь, красноперка, щука, карась). Эти доказательства свидетельствуют о том, что запасы Ценных видов находятся в депрессивном состоянии.

Продолжающееся снижение запасов ценных промысловых видов рыб западного района Каспия вызывает необходимость быстрейшего восстановления обширных нерестовых площадей внутренних водоемов. В настоящее время природный биопродуктивный потенциал внутренних водоемов бассейна р. Терек используется неэфффективно (рис.1.).

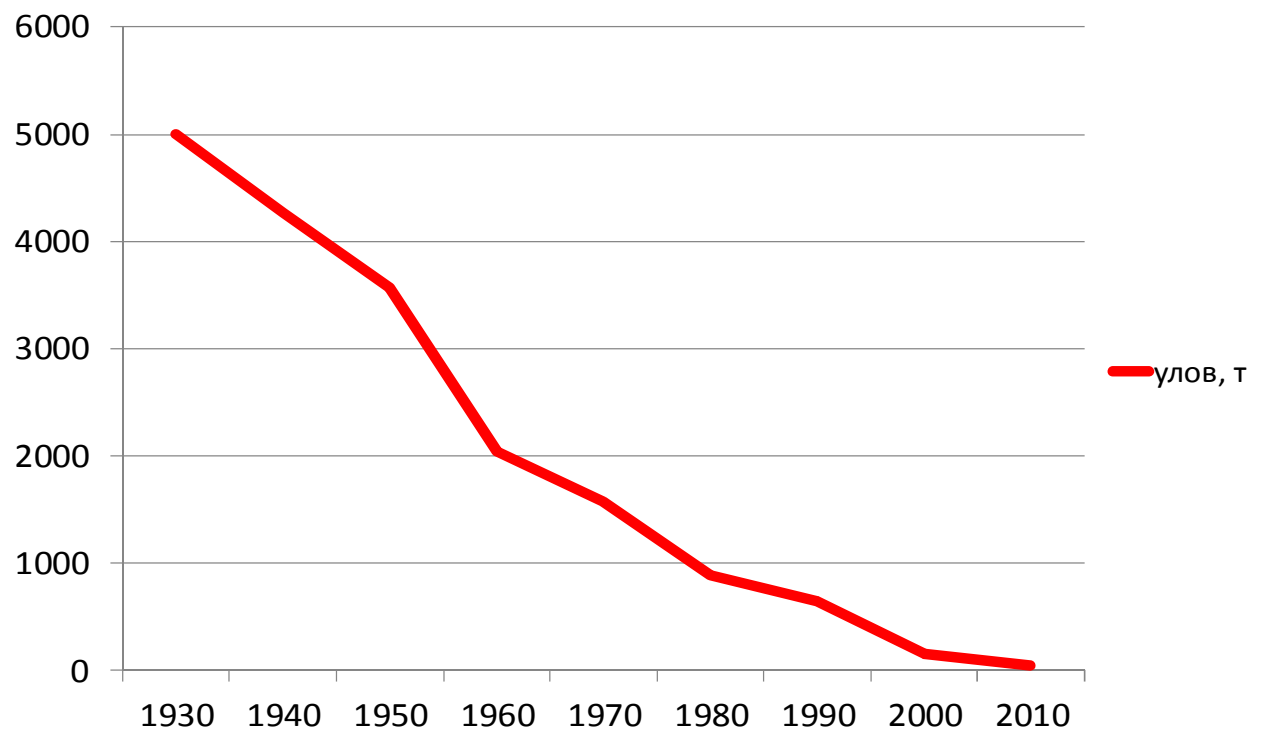

Рисунок 1 - Улов промысловых видов рыб

Для поднятия значения нерестово-выростных водоемов требуется осуществление комплексных рыбохозяйственных мероприятий, включающие в себя периодическое летование (через каждый десять лет) водоемов, усиление санитарного отлова хищных малоценных рыб, скашивание мягкой, жесткой растительности с последующей уборкой. Одновременно надо расширить, углубить водопадающих и рыбоходных каналов, которые будут способны попуску воды в объеме 80-40 m³ сс соответственно. Увеличение

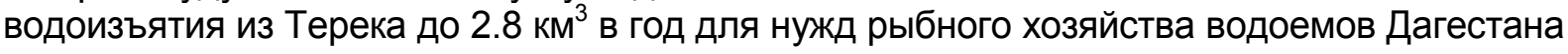
(Аракумские, Нижнетерские, Каракольский, Северный Аграхан и Южный Аграхан) будет 
способствовать заметному повышению уровня воспроизводства ценных видов рыб, а также разгрузка паводковых пиков в низовьях реки, которые проводят катастрофическим последствиям и большим фринансовым затратам.

Таблица 1 - Сравнительные данные рыбопродуктивности и уловов рыб во внутренних водоемах бассейна р. Терек в годы с относительно сохраненным естественным режимом (1940-1947) и в период после зарегулирования стока реки и ввода в эксплуатацию в нерестово- выростных водоемов (1965-2010)

\begin{tabular}{|c|c|c|c|c|c|}
\hline \multirow{2}{*}{ Показатели } & \multicolumn{5}{|c|}{ Периоды, годы промысла } \\
\hline & $1940-1947$ & $1965-1970$ & $1971-1980$ & $1981-1990$ & $1991-2010$ \\
\hline Уловы, тыс. т & 3,494 & 0,875 & 0,772 & 0,466 & 0,078 \\
\hline Площадь водоемов, га & 100000 & 40700 & 40700 & 40700 & 40700 \\
\hline Рыбопробуктивность, кг/га & 34,9 & 21,5 & 19,0 & 11,4 & 1,9 \\
\hline
\end{tabular}

Для улучшения водоустройства реки с меньшими материальными затратами необходимо строить дублирующий вал с правой стороны от Каргалинской плотины до Южного Аграхана шириной от 5 до 10 км. Свежезалитые пойменные участки могут быть использованы проходными, полупроходными рыбами под нерестилища. После спада паводков их можно использовать под сенокосы и пастбища. Для борьбы с чрезмерной зарастаемостью и получения дополнительной рыбной продукции, водоемы необходимо зарыблять также растительноядными рыбами из расчета 250-350 экз. на га белого амура и 100-150 экз/га толстолобиков.

Построенные на месте разрозненных озер в дельте Терека экологические условия регулируемых искусственных нерестово-выростных водоемов зависят от гидрологического режима реки. Аракумские НВВ были сданы в эксплуатацию 1965 г., Нижнетерские- в 1970 г., Каракольский - в 1977 г.

Рыбоводно-биологическое обоснование по возможной рыбопродуктивности нерестово-выростных водоемов (HBB) при измененном гидрологическом режиме строился нами на основании средних многолетних данных по вылову, процентному соотношению в уловах, по урожайности поколений каждого видов рыб.

При создании оптимальных условий в водоемах для естественного воспроизводства продуктивность по кутуму можно довести до 13,5 кг/га, по рыбцу - 7,9 кг/га, лещу - 20,1 кг/га, вобле - 3,6 кг/га, сазану - 60 кг/га, судаку - 7,0 кг/га, сому - 7,2 кг/га, щуке - 13,7 кг/га, жереху - 4,9 кг/га, по мелким пресноводным рыбам - 9,8 кг/га. В целом, при создании оптимальных условий в водоемах рыбопродуктивность их может увеличена до 148,0 кг/га.

Таблица 2 - Выход молоди при оптимальной водообеспеченности в водоемах

\begin{tabular}{|c|c|c|c|c|c|c|c|c|}
\hline 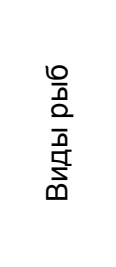 & 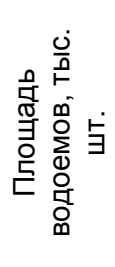 & 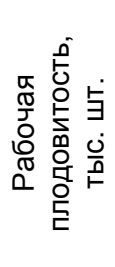 & 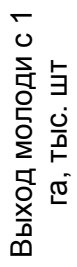 & 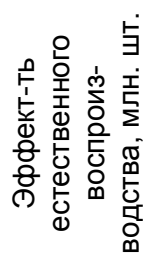 & 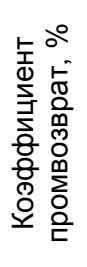 & 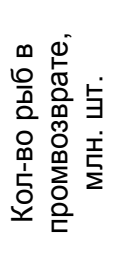 & 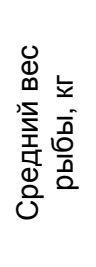 & 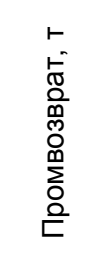 \\
\hline Кутум & 42 & 99,3 & 1,0 & 42,0 & 1 & 0,42 & 1,35 & 567,0 \\
\hline Рыбец & 42 & 33,0 & 2,2 & 92,4 & 3 & 2,77 & 0,120 & 332,4 \\
\hline Лещ & 42 & 136,0 & 2,3 & 96,6 & 2 & 1,92 & 0,44 & 844,8 \\
\hline Сазан & 42 & 345,5 & 1,0 & 42,0 & 4 & 1,68 & 1,5 & 2520,0 \\
\hline Вобла & 42 & 35,7 & 2,4 & 100,8 & 1 & 100,8 & 1,15 & 151,2 \\
\hline Судак & 42 & 237,0 & 0,2 & 8,4 & 4 & 0,336 & 0,88 & 295,7 \\
\hline COM & 42 & 95,0 & 0,1 & 4,2 & 4 & 0,168 & 1,8 & 302,4 \\
\hline щука & 42 & 97,3 & 0,2 & 8,4 & 4 & 0,336 & 1,6 & 537,6 \\
\hline Жepex & 42 & 92,3 & 0,1 & 4,2 & 4 & 0,168 & 1,23 & 206,6 \\
\hline Прочие & 42 & 100,0 & 0,7 & 29,4 & 4 & 1,176 & 0,35 & 411,6 \\
\hline Итого & 42 & - & - & 428,4 & $\begin{array}{l}\cdots \\
-\end{array}$ & 9,982 & - & 6169,3 \\
\hline
\end{tabular}

При рекомендуемых нами объемах водопотребления $\left(2,8 \mathrm{~km}^{3} /\right.$ год $)$ и при 
проведении всех отмеченных выше рыбоводно-мелиоративных мероприятий выход молоди от естественного нереста проходных, полупроходных и озерно-речных рыб составит 428,4 млн. экз., промвозврат - 9,982 млн. экз. или 6,2 тыс.т.

Нерестово-выростные водоемы бассейна реки Терек предназначены для воспроизводства полупроходных рыб с учетом их привязанности к высокопродуктивной части Северного Каспия, где имеются благоприятные условия обитания и нагула молоди и взрослых рыб. Поэтому главная задача заключается в обеспечении богатых пастбищ Северного Каспия молодью ценных видов за счет расширения площадей пресноводных водоемов для естественного размножения рыб.

Повышение значения внутренних водоемов особенно важно и актуально, когда территориальные воды России на Каспии больше охватывают опресненные районы моря, где влияние гребневика мнемиопсиса весьма ограничено. Целесообразно установить статус водоемов и определить необходимый комплекс мер по мелиоративному улучшению состояния водоемов.

\section{БИБЛИОГРАФИЯ}

[1] Абдусамадов А. С., Мирзоев М. 3., Мусаев П. Г., Кайтмазов М.М., Современное состояние и перспективы рыбохозяйственного использования внутренних водоемов Теркского района Каспийского бассейна./ Современные проблемы и перспективы развития животноводства и аквакультуры, Махачкала, 2012. с. 9699.

[2] Бивертон Р., Холт С. Обзор методов определения смертности облавливаемых популяций рыб. Источники возникновения ошибок при взятии проб из уловов. М.: Пищевая промышленность , 1958. - 57 с.

[3] Дементьева М. А. Опыт тестирования фризиологического состояния сеголеток карпа в условиях тяжелых вод по их устойчивости к повышенной соленности.

[4] Коблицкая А. Ф. Изучение нерестилищ пресноводных рыб. - Астрахань, 1963. c.61.

[5] Кожин Н.И. Итоги и задачи научно- исследовательских работ по производству рыбных запасов в южных водоемах в связи с гидростроительством.

[6] Кушнаренко А. И. Оценка численности рыб по уловам пассивными орудиями лова / Кушнаренко А.И. , Лугарев Е.С. // Вопросы ихтиологии. - 1983. - т. 23. - Вып. 6 c. 921- 926.

[8] Малкин Е.М. Репродуктивная и численная изменчивость промысловых популяционных рыб. , 1999. 137 с.

[9] Монастырский Г. Н. Запасы воблы северного Каспия и методы их оценки// Труды ВНИРО - Т. 11. 1940 , с 115-170.

[10] Правдин И.Ф. Руководство по изучению рыб (преимущественно пресноводных) / Правдин И.Ф. под ред. Дрягина П.А. и Покровского В.В. ( Издат-во 4-е, перераб. и дополн.) - М.: « Пищевая промышленность». - 1966. - 37 с.

[11] Столяров И. А. Состояние запасов рыб (кроме осетровых) во внутренних водоемах Дагестана. Прогноз добычи их, изучение динамики численности и биологическое обоснование регулирования рыболовства (промежуточный отсчет).- Махачкала, 1978,137 с.

[12] Чугунова Н. И. Методика изучения возраста и роста рыб.- М.: Советская наука, 1952. - $164 \mathrm{c}$.

[13] Чугунова Н. И. Руководство по изучению возраста и роста рыб. - М.: Изд-во АН СССР, 1959.- 164 C.

[14] Шмальгаузен И. И. Рост животных. - М.-Л., 1935. - с. 8-60. 